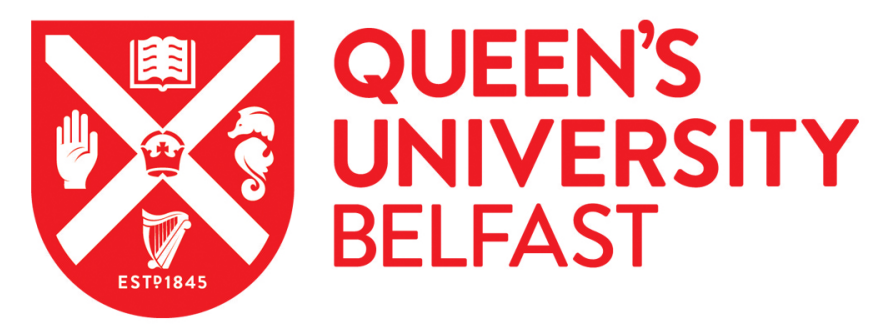

\title{
Evaluation of scenarios for improving energy efficiency and reducing exhaust emissions of a passenger car fleet: A methodology
}

Mijailovic, R., Marković, N., Pesic, D., \& Vlajic, J. (2019). Evaluation of scenarios for improving energy efficiency and reducing exhaust emissions of a passenger car fleet: A methodology. Transportation Research Part $D, 73$, 352-366. https://doi.org/10.1016/j.trd.2019.07.005

Published in:

Transportation Research Part D

Document Version:

Peer reviewed version

Queen's University Belfast - Research Portal:

Link to publication record in Queen's University Belfast Research Portal

Publisher rights

Copyright 2019 Elsevier

This manuscript is distributed under a Creative Commons Attribution-NonCommercial-NoDerivs License

(https://creativecommons.org/licenses/by-nc-nd/4.0/), which permits distribution and reproduction for non-commercial purposes, provided the author and source are cited.

\section{General rights}

Copyright for the publications made accessible via the Queen's University Belfast Research Portal is retained by the author(s) and / or other copyright owners and it is a condition of accessing these publications that users recognise and abide by the legal requirements associated with these rights.

Take down policy

The Research Portal is Queen's institutional repository that provides access to Queen's research output. Every effort has been made to ensure that content in the Research Portal does not infringe any person's rights, or applicable UK laws. If you discover content in the Research Portal that you believe breaches copyright or violates any law, please contact openaccess@qub.ac.uk. 


\title{
Evaluation of scenarios for improving energy efficiency and reducing exhaust emissions of a passenger car fleet: A methodology
}

\author{
Radomir Mijailović(1), Nenad Marković(1), Dalibor Pešić(1), Jelena V. Vlajić( ${ }^{(2)}$ \\ ${ }^{(1)}$ University of Belgrade - The Faculty of Transport and Traffic engineering, Serbia \\ ${ }^{(2)}$ Queen's University Belfast, UK
}

\begin{abstract}
Improvement of energy efficiency and exhaust emissions reduction are environmental targets of utmost importance in the transport and traffic sectors. The literature suggests that there is a need for the development of a general methodology that can be used to evaluate and compare scenarios for the reduction of the environmental impact caused by fossil-fuel usage of passenger car fleet. We develop such a methodology, which assesses the external costs of four combustion products (carbon dioxide, carbon monoxide, nitrogen oxides and hydrocarbons) as well as fuel consumption costs. In this study, we applied this methodology to evaluate and compare five scenarios. The methodology was tested for the case of the Serbian passenger car fleet. Serbia was selected as a country with the passenger car fleet primarily consisted of fossil-fuelled passenger cars. In addition, Serbia is a country in which rising demand for cars is met through the import of second-hand cars. We found that the only scenario which could result in a positive solution of the given problem is the "reduction of the total number of passenger cars in the fleet of a country" scenario. Moreover, the purchase of new cars and import of second-hand cars cannot result in significant positive effects. The results obtained for the case of Serbia can provide an important insight into the environmental effects of passenger car fleets for countries primarily using fossilfuelled cars, in which the demand for cars is met mostly through the import of second-hand cars.
\end{abstract}

Keywords: methodology, passenger cars, energy efficiency, exhaust emission. 


\section{Introduction}

The most important goals concerning global environmental problems include the reduction of exhaust emissions and the improvement of energy efficiency. A passenger car fleet is the main source of environmental burden from combustion fuel products. Exhaust emissions, energy efficiencies and average ages of passenger car fleets differ significantly between countries (Zervas, 2010; Melhart et al, 2011). The fossil-fuelled passenger cars will remain the prime source of carbon dioxide emissions in the coming decades, with a predicted contribution of over $83 \%$ of total carbon dioxide emissions in 2050 (Hao et al., 2015). An encouraging fact is that it is possible to keep the carbon dioxide emission produced by passenger cars worldwide on a level that is acceptable and sustainable (Hao et al., 2015). An important question is whether the above conclusion can be applied to improve energy efficiency and reduce exhaust emissions of passenger car fleets.

The reduction of exhaust emissions and improvement of energy efficiency of passenger cars has been analyzed by several authors. Models were developed, along with methodologies and scenarios of various scales of complexity. Below we present the key studies and conclusions.

A strand of literature investigates the development of models related to an optimal fleet conversion policy. Kim et al. (2004) selected the total life cycle emissions as an objective function for the optimization purpose. The authors, separately analyzing the four main combustion products (carbon dioxide, carbon monoxide, nitrogen oxides and non-methane hydrocarbons). The model developed in the above research could be improved by not analyzing combustion products separately. Namely, Mijailović (2013) analyzed the optimal lifetime of a passenger car and suggested a generalized model by using the total life cycle emission of carbon dioxide as the objective function. Mijailović (2013) showed that increasing the number of included combustion products would not improve model applicability. In addition, the availability of data is a major constraint for its wider use. This was confirmed by Vinoles-Cebolla et al. (2015). They calculated emissions during a car's life cycle and suggested a method that includes seven combustion products (carbon dioxide, carbon monoxide, nitrogen oxides, particulate matter, methane, non-methane 
volatile organic and sulphur oxide). Their model incorporated detailed car data, such as engine technology, year of manufacture, weight, fuel type etc. The authors implemented this method for three internal combustion engine cars. We seek to include a larger number of combustion products into a generalised model.

To evaluate the given methodology, a single cost function would be preferred for analysis. In order to connect different combustion products into a single objective cost function, one can internalize externalities. For instance, Kaplanović and Mijailović (2012) analyzed annual car circulation taxes. They suggest a new methodology based on the internalization of externalities, using approximation functions of average combustion products (carbon dioxide, carbon monoxide, nitrogen oxides, hydrocarbons and particulate matter) based on vehicle age. The approximation functions depend on car`s age, fuel type, and engine displacement. Maintenance was omitted from this research and included in subsequent research by Mijailović (2013). Mitropoulos and Prevedouros (2015) determined life cycle emissions, as well as the societal and consumer life cycle cost. The authors proposed a methodology that included first cost, insurance cost, maintenance cost, retail cost, external costs and fuel efficiency of the vehicle. The methodology was implemented on seven types of light duty vehicles.

Some research demonstrated that a modification of parameters - such as age, weight and mileage of a vehicle - can produce a positive environmental outcome. Zachariadis et al. (2001) defined two groups of parameters that influence vehicle emissions: age parameters (average age of a vehicle fleet, the decrease of the average specific mileage with age, degradation of emission control systems with age) and technology parameters (introduction of new technologies, implementation of enhanced inspection and maintenance, introduction of cleaner fuels). A vehicle weight reduction enables an abatement of carbon dioxide emission (Mijailović, 2013) and improves fuel consumption (Tolouei et al, 2009). Zervas and Lazarou (2008) have concluded that a higher reduction of carbon dioxide emission is reached through the decrease of the car weight than through the expectation based on decreasing fuel consumption. This is in line with Cheah and Heywood (2011), who 
analyzed the US passenger car fuel economy standard up to 2030. They concluded that new cars must become lighter and more fuel-efficient. They also concluded that every $100 \mathrm{~kg}$ of passenger car weight reduction will produce a $0.31 \mathrm{l} / 100 \mathrm{~km}$ reduction of fuel consumption by 2030 . This research proved the need for new car fleets that emit less carbon dioxide. Many countries recognized this and introduced special programs (Magueta et al., 2018).

A few studies in the literature introduce useful scenarios that improve energy efficiency and reduce exhaust emissions. Kwon (2005) analyzed the carbon dioxide emission trends from cars and built various scenarios. These scenarios were compared using the "I=PAT" identity ("Impact = Population x Affluence x Technology"). The author considered the following scenarios: car travel reduction initiative, large impact of telecommuting technology, sustainable planning, narrower car selection, gradual and rapid shift to the alternative-fuelled vehicles. Kwon concluded that the best results were not obtained in each of the individual scenarios but in the combined "sustainable planning - rapid shift to alternative-fuel vehicles" scenario.

Hao et al. (2016) analyzed cars' carbon dioxide emissions by 2050, analyzing cars with different propulsion technologies (internal combustion, electric and fuel cell). The authors considered three possible scenarios: BAU ("future trends with policy implementation and technology improvement continuing their current trends"); frozen ("vehicle use, energy intensity and technology penetration are frozen"); and optimal ("impacts from policy and technology are maximized to full potential"). Previous scenarios did not take into account the countries where the rising demand for cars is met through the import of second-hand cars.

In the relevant literature we identify a lack of general methodologies that can be used to evaluate scenarios for improving energy efficiency and exhaust emissions of passenger car fleets. Several authors analyzed the impact of a limited number of combustion products, but insufficient attention was given to the general impact of combustion products on the environment. The aim of this paper is address this gap in the literature. 
This research contributes to the transportation science by developing a general methodology for comparison of scenarios aimed to improve energy efficiency and reduce emissions of a passenger car fleet. Therefore, this methodology can be used for assessing the impact of a passenger car fleet on environmental pollution in any country. In addition, we show that the share of the external costs of carbon monoxide, hydrocarbons and nitrogen oxides emissions as a fraction of the total cost (being sum of the external costs of $\mathrm{CO}_{2}, \mathrm{CO}, \mathrm{HC}$ and $\mathrm{NO}_{\mathrm{x}}$ emissions, as well as the cost of fuel consumption) is negligible. We identify scenarios that can be applied for the case of a fossilfuelled passenger car fleet.

Our research also has practical significance. We gathered and analyzed the empirical data on the Serbian passenger car fleet. Serbia was selected as a representative case for two reasons: first, the number of the second-hand imported passenger cars is typically much higher than the number of new passenger cars; and, second, the passenger car fleet primarily consists of the fossil-fuelled passenger cars. Our analysis is relevant for two reasons: first, we provide a much deeper insight into the Serbian passenger car fleet than national statistical data shows; second, our analysis can be used to extrapolate data points of other similar countries where data is insufficiently available.

The paper is structured as follows: Section 2 contains a general methodology for comparison of scenarios aimed to improve energy efficiency and reduce emissions of a passenger car fleet. The methodology is based on a determination of the external costs of four combustion products (carbon dioxide, carbon monoxide, nitrogen oxides and hydrocarbons) as well as fuel consumption costs. In Section 3, the methodology is applied to the case of the Serbian passenger car fleet. We evaluate and compare six scenarios. In the final section, we present concluding remarks, limitations of the study and future research directions. 


\section{Methodology}

\subsection{Total cost}

The methodology presented below is based on the total cost related to the passenger car fleet in a country $k$, in a year $T_{i}$. In this section, we derive a representation of the total cost of a passenger car fleet.

Exhaust emissions, energy efficiencies and average ages of passenger car fleets differ between countries (Zervas, 2010; Melhart et al, 2011). As these values can be found in wide ranges, we introduce the term "average passenger car". The average passenger car of a country is a fictional passenger car, and the exhaust emissions, energy efficiency and age of that car are equal to the mean value of exhaust emissions, energy efficiencies and average age of the country passenger car fleet. To determine the average passenger car, we define a relation between carbon dioxide $\left(\mathrm{CO}_{2}\right)$, carbon monoxide $(\mathrm{CO})$, nitrogen oxides $\left(\mathrm{NO}_{\mathrm{x}}\right)$ and hydrocarbons $(\mathrm{HC})$ emissions and fuel consumption by considering the external costs of $\mathrm{CO}_{2}, \mathrm{CO}, \mathrm{HC}$ and $\mathrm{NO}_{\mathrm{x}}$ (Kaplanović and Mijailović, 2012) and the cost of fuel consumption.

The cost of the fuel consumption in country $k$, in year $T_{i}$ for the average passenger car is given by the expression:

$$
C f_{i, k}=e f_{i, k} \cdot q f_{i, k}, E U R / k m,
$$

where $e f_{i, k}$ (in EUR/l) is the fuel cost in country $k$, in year $T_{i}$ per liter, while $q f_{i, k}(l / \mathrm{km})$ is the specific fuel consumption of the average passenger car per $\mathrm{km}$ in country $k$, in year $T_{i}$. The fuel cost $\left(e f_{i, k}\right)$ is determined based on the predictions of future directions in the fuel price for a given country.

The external costs of $\mathrm{CO}_{2}, \mathrm{CO}, \mathrm{HC}$ and $\mathrm{NO}_{\mathrm{x}}$ in country $k$, in year $T_{i}$ for the average passenger car can be written by the following equations (Kaplanović and Mijailović, 2012): 


$$
\begin{aligned}
& \mathrm{ECCO}_{i, k}=e c C O 2_{i} \cdot q C O 2_{i, k}, \\
& \mathrm{ECCO}_{i, k}=e c C O_{i} \cdot q C O_{i, k}, \\
& \mathrm{ECHC}_{i, k}=e c H C_{i} \cdot q H C_{i, k}, \\
& \mathrm{ECNO}_{i, k}=e c C O 2_{i} \cdot q N O x_{i, k}, E U R / \mathrm{km} .
\end{aligned}
$$

Here the values of $e c \mathrm{CO}_{i}, e c \mathrm{CO}_{i}, e c \mathrm{HC}_{i}, e_{c N O x_{i}}($ in $\mathrm{EUR} / \mathrm{kg}$ ) are the external costs per kilogram of the $\mathrm{CO}_{2}, \mathrm{CO}, \mathrm{HC}$ and $\mathrm{NO}_{x}$ emissions respectively, for a year $T_{i}$. The values of $q C O 2_{i, k}, q C O_{i, k}$, $q H C_{i, k}, q N O x_{i, k}(\mathrm{~kg} / \mathrm{km})$ are respective specific emissions of $\mathrm{CO}_{2}, \mathrm{CO}, \mathrm{HC}$ and $\mathrm{NO}_{\mathrm{x}}$ in country $k$, in year $T_{i}$, expressed in $\mathrm{kg} / \mathrm{km}$ for the average passenger car.

The external cost per kilogram of the $\mathrm{CO}_{2}, \mathrm{CO}, \mathrm{HC}$ and $\mathrm{NO}_{x}$ emissions in 2007 can be found in the study of Kaplanović and Mijailović (2012). By using (2), the external cost of exhaust emissions in country $k$, in year $T_{i}$ for the average passenger car be written in the form:

$$
E C_{i, k}=E C C O 2_{i, k}+E C C O_{i, k}+E C H C_{i, k}+E C N O x_{i, k}, E U R / k m .
$$

The total cost in country $k$, in year $T_{i}$ for the average passenger car is represented by a sum of the costs of fuel consumption (1) and external costs of exhaust emissions (3). Based on the equations (1), (2) and (3), the total cost in country $k$, in year $T_{i}$ for the average passenger car can be written in the following form:

$$
\begin{aligned}
C_{i, k}= & e f_{i, k} \cdot q f_{i, k}+e c C O 2_{i} \cdot q C O 2_{i, k}+e c C O_{i} \cdot q C O_{i, k}+ \\
& +e c H C_{i} \cdot q H C_{i, k}+e c N O x_{i} \cdot q N O x_{i, k}, E U R / \mathrm{km} .
\end{aligned}
$$

The emissions deteriorate with the age of passenger cars (Zachariadis et al., 2001; BorkenKleefeld and Chen, 2015). Therefore, the total cost in country $k$, in year $T_{i}$ for the average passenger car also depends on the average age of passenger cars. The emissions functional dependences on the average age of passenger cars are given by expressions (Kaplanović and Mijailović, 2012):

$$
\begin{aligned}
& q C O 2_{i, k, h}=q C O 2_{i, k, h}^{\text {new }} \cdot\left(1+c_{h} \cdot t_{i, k, h}^{d_{h}}\right), \quad q C O_{i, k}=q C O_{i, k}^{\text {new }} \cdot\left(1+0.0305 \cdot t_{i, k}^{1.865}\right), \\
& q H C_{i, k}=q H C_{i, k}^{\text {new }} \cdot\left(1+0.121 \cdot t_{i, k}^{1.303}\right), \quad q N O x_{i, k}=q N O x_{i, k}^{\text {new }} \cdot\left(1+0.33 \cdot t_{i, k}\right),
\end{aligned}
$$


where $q C O 2_{i, k, h}^{\text {new }}, q C O_{i, k}^{\text {new }}, q H C_{i, k}^{\text {new }}$ and $q N O x_{i, k}^{\text {new }}$ denote respective specific $\mathrm{CO}_{2}, \mathrm{CO}, \mathrm{HC}$ and $\mathrm{NO}_{\mathrm{x}}$ emissions in country $\mathrm{k}$, in year $T_{i}$, expressed in $\mathrm{kg} / \mathrm{km}$ for an average new passenger car. The $t_{i, k, h}$ is the average age of passenger cars in country $k$, in year $T_{i}$ and for a type $h$. The $h$ is the fuel and engine displacement type (Table 1), and $c h, d_{h}$ are parameters (Table 1).

\begin{tabular}{|c|c|c|c|c|}
\hline$h$ & fuel type & engine displacement, $\mathrm{cm}^{3}$ & $c$ & $d$ \\
\hline 1 & petrol & $<1400$ & 0.0215 & 1 \\
\hline 2 & petrol & $1400 \ldots 2000$ & 0.0256 & 1 \\
\hline 3 & petrol & $>2000$ & 0.00096 & 2 \\
\hline 4 & diesel & $<2000$ & 0.00027 & 3 \\
\hline 5 & diesel & $\geq 2000$ & 0.00029 & 3 \\
\hline
\end{tabular}

Table 1. The fuel and engine displacement type $(h)$ and parameters $(c, d)$ (Mijailović, 2013, Kaplanović and Mijailović, 2012)

The specific $\mathrm{CO}_{2}$ emission in country $k$, in year $T_{i}$ depends on fuel type and engine displacement (Mijailović, 2013). The specific $\mathrm{CO}_{2}$ emission in country $k$, in year $T_{i}$, and for type $h$ of the average new passenger car can be written as follows (Mijailović, 2013):

$$
q C O 2_{i, k, h}^{\text {new }}=0.001 \cdot M_{i, k, h} \cdot w_{1, h} \cdot\left(T_{i}-t_{i, k, h}-1994\right)^{w_{2, h}}
$$

where $M_{i, k, h}$ is the average passenger car weight in country $k$, in year $T_{i}$ and for type $h$, while the coefficients takes the following values

$-\quad w_{1, h}=0.194, w_{2, h}=-0.12$ for $h=1,2,3$,

$-\quad w_{1, h}=0.157, w_{2, h}=-0.153$ for $h=4,5$.

In line with (Olsthoorn 2003) and Mickunaitis, (2007), we assume the relation of the specific fuel consumption and specific $\mathrm{CO}_{2}$ emission to be linear. Based on Mickunaitis et al. (2007), the specific fuel consumption of the average passenger car per $k m$ in country $k$, in year $T_{i}$ can be written as:

$$
q f_{i, k, h}=\frac{q C O 2_{i, k, h}+b_{h}}{a_{h}}, l / k m .
$$

The coefficients $a_{h}$ and $b_{h}$ depend on the type of an engine/car:

- $\quad a_{h}=24.173 \mathrm{~kg} / \mathrm{l}, b_{h}=2.1889 \mathrm{~kg} / \mathrm{km}-\operatorname{petrol} \operatorname{car}(h=1,2,3)$,

- $\quad a_{h}=26.87 \mathrm{~kg} / \mathrm{l}, b_{h}=0.94647 \mathrm{~kg} / \mathrm{km}-\operatorname{diesel} \operatorname{car}(h=4,5)$. 
The number of passenger cars in country $k$, in year $T_{i}$, and for type $h$ can be written as:

$$
N_{i, k, h}=N_{i-1, k, h}+N n_{i, k, h}+N i m_{i, k, h}-N e x_{i, k, h}-N s_{i, k, h},
$$

where:

- $\quad N_{i-1, k, h}-$ the number of passenger cars in country $k$, in year $T_{i-1}$ and for type $h$,

- $\quad N n_{i, k, h}-$ the number of new passenger cars in country $k$, in year $T_{i}$ and for type $h$,

- $\quad \operatorname{Nim}_{i, k, h}$ - the number of second-hand passenger cars imported to country $k$, in year $T_{i}$ and for type $h$,

- $\quad N e x_{i, k, h}$ - the number of second-hand passenger cars exported from country $k$, in year $T_{i}$ and for type $h$,

- $\quad N s_{i, k, h}-$ the number of scraped old passenger cars in country $k$, in year $T_{i}$ and for type $h$.

These numbers of passenger cars can be determined as:

$$
\begin{array}{ll}
N n_{i, k, h}=\Delta n_{i, k, h} \cdot N_{i-1, k, h}, & \operatorname{Nim}_{i, k, h}=\Delta i m_{i, k, h} \cdot N_{i-1, k, h}, \\
N e x_{i, k, h}=\Delta e x_{i, k, h} \cdot N_{i-1, k, h}, & N s_{i, k, h}=\Delta s_{i, k, h} \cdot N_{i-1, k, h},
\end{array}
$$

where

- $\Delta n_{i, k, h}-$ the rate of buying new passenger cars in country $k$, in year $T_{i}$ and for type $h$,

- $\Delta i m_{i, k, h}-$ the rate of second-hand passenger cars imported to country $k$, in year $T_{i}$ and for type $h$,

- $\Delta e x_{i, k, h}-$ the rate of second-hand passenger cars exported from country $k$, in year $T_{i}$ and for type $h$,

- $\Delta s_{i, k, h}-$ the scrappage rate in country $k$, in year $T_{i}$ and for type $h$.

The number of passenger cars in country $k$, in year $T_{i}$ is given by the expression:

$$
N_{i, k}=\sum_{h=1}^{5} N_{i, k, h}
$$

The average age of passenger cars in country $k$, in year $T_{i}$ and for type $h$ can be written as: 


$$
t_{i, k, h}=\frac{\left(1-\Delta e x_{i, k, h}-\Delta s_{i, k, h}\right) \cdot\left(t_{i-1, k, h}+1\right)+\Delta i m_{i, k, h} \cdot \operatorname{tim}_{i, k, h}}{1+\Delta n_{i, k, h}+\Delta i m_{i, k, h}-\Delta e x_{i, k, h}-\Delta s_{i, k, h}}
$$

where timi,k,h denotes the average age of second-hand passenger cars imported to country $k$, in year $T_{i}$ and for type $h$. The average age of passenger cars in country $k$, in year $T_{i}$ is determined as

$$
t_{i, k}=\frac{\sum_{h=1}^{5} t_{i, k, h} \cdot N_{i, k, h}}{N_{i, k}}
$$

The specific $\mathrm{CO}_{2}$ emission in country $k$, in year $T_{i}$, expressed in $\mathrm{kg} / \mathrm{km}$ for the average passenger car, is given by the expression:

$$
q C O 2_{i, k}=\frac{\sum_{h=1}^{5} N_{i, k, h} \cdot q C O 2_{i, k, h}}{N_{i, k}}
$$

Finally, based on equations (5), (6), (7) and (13), the total cost in country $k$, in year $T_{i}$ for the average passenger car (4) can be rewritten into the following form:

$$
\begin{aligned}
C_{i, k}= & \frac{0.001}{N_{i, k}}\left[\sum_{h=1}^{5} N_{i, k, h} \cdot M_{i, k, h} \cdot w_{1, h} \cdot\left(\frac{e f_{i, k}}{a_{h}}+e c C O 2_{i}\right) \cdot\left(T_{i}-t_{i, k, h}-1994\right)^{w_{2, h}} \cdot\left(1+c_{h} \cdot t_{i, k, h}^{d_{h}}\right)\right]+ \\
& +\frac{e f_{i, k}}{N_{i, k}} \cdot \sum_{h=1}^{5} \frac{N_{i, k, h} \cdot b_{h}}{a_{h}}+e c C O_{i} \cdot q C O_{i, k}^{\text {new }} \cdot\left(1+0.0305 \cdot t_{i, k}^{1.865}\right)+ \\
& +e c H C_{i} \cdot q H C_{i, k}^{\text {new }} \cdot\left(1+0.121 \cdot t_{i, k}^{1.303}\right)+e c N O x_{i} \cdot q N O x_{i, k}^{\text {new }} \cdot\left(1+0.33 \cdot t_{i, k}\right), E U R / k m .
\end{aligned}
$$

The total cost of the passenger car fleet in country $k$, in year $T_{i}$ can be written as:

$$
C F_{i, k}=N_{i, k} \cdot C_{i, k}
$$

Now, if we apply the expression (14), the total cost of the passenger car fleet in country $k$, in year $T_{i}$ obtains its final form given by

$$
\begin{aligned}
& C F_{i, k}=0.001\left[\sum_{h=1}^{5} N_{i, k, h} \cdot M_{i, k, h} \cdot w_{1, h} \cdot\left(\frac{e f_{i, k}}{a_{h}}+e c C O 2_{i}\right) \cdot\left(T_{i}-t_{i, k, h}-1994\right)^{w_{2, h}} \cdot\left(1+c_{h} \cdot t_{i, k, h}^{d_{h}}\right)\right]+ \\
& \quad+e f_{i, k} \cdot \sum_{h=1}^{5} \frac{N_{i, k, h} \cdot b_{h}}{a_{h}}+N_{i, k} \cdot\left[e c C O_{i} \cdot q C O_{i, k}^{\text {new }} \cdot\left(1+0.0305 \cdot t_{i, k}^{1.865}\right)+\right. \\
& \left.\quad+e c H C_{i} \cdot q H C_{i, k}^{\text {new }} \cdot\left(1+0.121 \cdot t_{i, k}^{1.303}\right)+e c N O x_{i} \cdot q N O x_{i, k}^{\text {new }} \cdot\left(1+0.33 \cdot t_{i, k}\right)\right], E U R / k m
\end{aligned}
$$


The total cost of the passenger car fleet in country $k$, in year $T_{i}(16)$ represents a value which can determine the effects of scenarios aimed to solve the problems related to energy efficiency and exhaust emissions of the passenger car fleet of any country.

\subsection{Application procedure of the methodology}

The methodology consists of five phases. In the Phase 1, the application of the equation (16) requires data related to the passenger car fleet of the observed country, as well as country specific data, such as GDP per capita and population size. In order for the model assumptions to be met, the covered period of the data collected (Phase 1) should be at least equal to the average age of the passenger car fleet in the observed country. Phase 2 (total cost for the average new passenger car) includes a total cost determination for average new passenger cars in all foreign countries from which second-hand passenger cars are imported. In the Phase 3 (trends), it is necessary to analyze the trend of changing the number of passenger cars $\left(N_{i, k, h}, N n_{i, k, h}, N i m_{i, k, h}, N e x_{i, k, h}, N s_{i, k, h}\right)$ depending on the year $\left(T_{i}\right)$. Based on the analysis of the results obtained in previous phases, Phase 4 formulates relevant scenarios for replacement of the passenger car fleet, aimed to improve energy efficiency and exhaust emissions. In Phase 5 (evaluation of scenarios), one first estimates the change of the total cost of the passenger car fleet (16) for each proposed scenario from Phase 4. Second, one compares the estimated scenarios to rank these scenarios.

\section{Application of the methodology - the case study of the Serbian passenger car fleet}

The methodology was applied to the case of the Serbian passenger car fleet. The practical application of each phase is described below.

\subsection{Phase 1: Data collection}

Phase 1 of the methodology focusses on data collection. There are various sources of data. A commonly used source of data related to the number of passenger cars in a country is the statistical office of that country. A problem that can arise during the implementation of this phase is that the 
data can be incomplete. For this reason, additional information needs to be collected at inspection centers directly. During a technical inspection of a car at an inspection center, it is possible to access car documentation, as well as conduct interviews with car owners.

In this paper, data was collected in two ways. First, official statistical data was obtained from the Statistical Office of the Republic of Serbia (2018). The collected data on the Serbian secondhand passenger car fleet from this source was deemed incomplete. Therefore, we performed additional data collection related to the Serbian passenger car fleet at car inspection centers.

The data collected for each car was grouped into two data sets. The first data set was collected from the car documentation: model, type, year of passenger car production, weight, fuel type, engine displacement and engine power. The second data set was collected by interviews with car owners. The questionnaire contained eight questions related to fuel consumption, emission standard, origin of a car ("Was the car purchased as new in Serbia?"), year of import, country of origin, and the regularity of maintanance.

The reliability of the results obtained by interviews was enhanced with two control questions. The first question was related to fuel consumption. This information was compared to the fuel consumption data from the car catalogue. To clean the sample, we removed data for the cars with a discrepancy between the reported and catalogue values of fuel consumption greater than $30 \%$. The answer to the second control question, "Was the car purchased as new in Serbia?", was compared with the answer to the question: "When was the car imported?".

Data collection was conducted during the years 2014 and 2015 in 22 Serbian inspection centers, and was performed by 16 trained junior researchers who had access to inspection centers, car documentation and car-owners. Initially, the sample consisted of 8,038 passenger cars. From this sample, the data related to 227 passenger cars was removed due to incompleteness or illogical answers to the control questions. Therefore, the final refined sample used in the analysis consisted of 7,811 passenger cars. Considering that the fleet size of passenger cars in Serbia is $1,833,219$ 
vehicles (2015), the collected sample is adequate for a confidence interval of $95 \%$, with the assumed error margin of 5\%.

\subsection{Phase 2: Total cost for the average new passenger car}

In the Phase 2, we determine the total cost for average new passenger cars in all foreign countries from which cars were imported as second-hand passenger cars. In order to estimate the second-hand passenger car emissions and fuel consumption, we analyze the average new passenger car in the EU and in the selected EU countries in the period of 2001-2012 (Mock, 2014).

$\mathrm{CO}, \mathrm{HC}$ and $\mathrm{NO}_{\mathrm{x}}$ emissions for the average new passenger car had a decreasing trend until 2007, while $\mathrm{CO}_{2}$ emission and fuel consumption have been decreasing until 2012 (Mock, 2014). The data analysis shows an interesting result: the largest change is observed for $\mathrm{NO}_{\mathrm{x}}$ emissions, which were reduced by $62 \%$ in the period of $2001-2012$, while emissions of $\mathrm{CO}_{2}, \mathrm{HC}$ and $\mathrm{CO}$, as well as the fuel consumption, had a lower reduction (by $21 \%, 7 \%, 5 \%$, and $21 \%$, respectively). The discrepancy between numerical values of $\mathrm{CO}_{2}$ emission (Mock, 2014) and the results obtained in the papers of Fontaras and Samaras (2007), and Schipper (2011), is lower than 2.4\%.

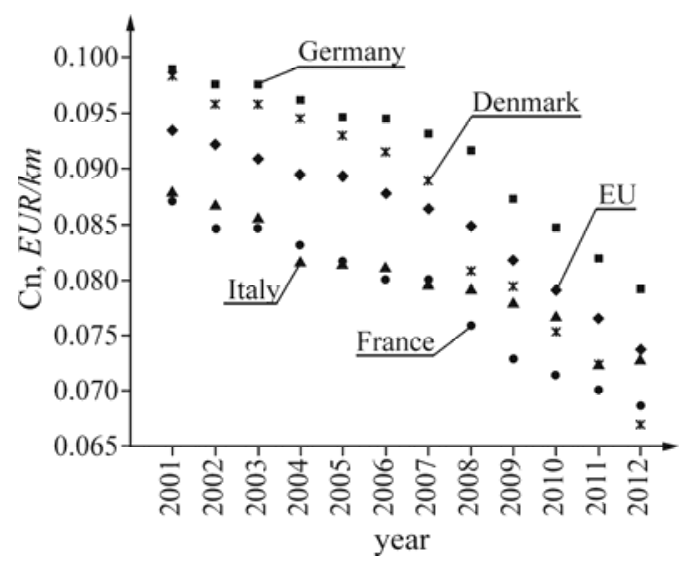

Figure 1. A total cost for the average new passenger car per country in the period 20012012

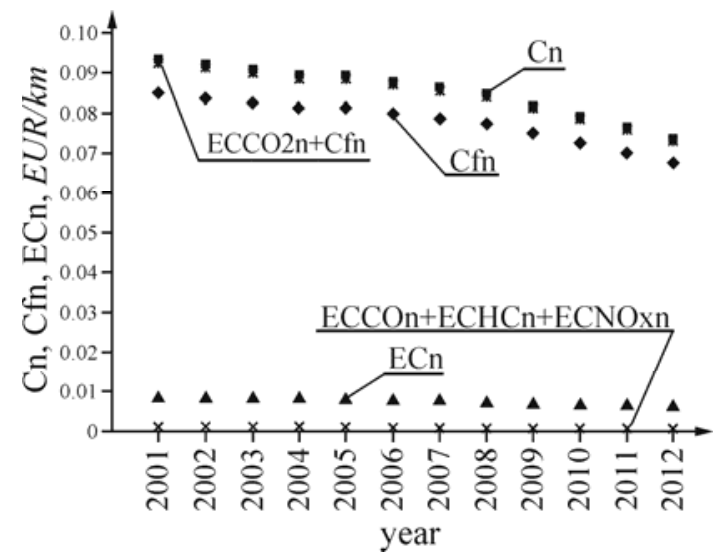

Figure 2. Dependencies of the EU`s total cost, the cost of the fuel consumption and external costs for the average new passenger car - yearly

The total cost trend for the average new passenger car in the EU was mostly decreasing in the period of 2001-2012 (Figure 1). For example, the total cost in 2001 was $0.094 \mathrm{EURO} / \mathrm{km}$, in 2007 
it decreased to $0.086 \mathrm{EURO} / \mathrm{km}$, and in 2012 to $0.074 \mathrm{EURO} / \mathrm{km}$. The analysis of total costs of individual EU countries also showed mostly decreasing trend, but there were significant differences. For example, the average new passenger car in Portugal had a range of low total cost values (from $0.088 \mathrm{EURO} / \mathrm{km}$ in 2001 to $0.066 \mathrm{EURO} / \mathrm{km}$ in 2012), while average passenger cars in Greece, Netherlands and Germany had much higher total cost values. For example, the average new car in Germany had a range of high values from $0.098 \mathrm{EUR} / \mathrm{km}$ in 2002 to $0.079 \mathrm{EUR} / \mathrm{km}$ in 2012 . The total cost for the average new passenger car in the EU was approximated based on the data using regression analysis (Mijailović, 2015):

$$
C n_{i, E U}=0.095-0,00173 \cdot\left(T_{i}-2001\right), R^{2}=0,95,
$$

where $T_{i}$ denotes the production year and $R^{2}$ is the coefficient of determination.

Figure 2 shows that the cost of fuel consumption $(C f n)$ represents approximately $91 \%$ of the total cost $(\mathrm{Cn})$, while the external costs related to $\mathrm{CO}, \mathrm{HC}$ and $\mathrm{NO}_{\mathrm{x}}$ is negligible (approximately $1 \%$ ). In addition, a specific fuel consumption is linearly dependent on a specific $\mathrm{CO}_{2}$ emission. Therefore, it can be concluded that the effectiveness of scenarios for solving the problems related to energy efficiency and exhaust emissions of passenger car fleets can be quantified by analyzing the specific fuel consumption change. Moreover, a reduction of passenger car fuel consumption results in a reduction of the external costs of exhaust emissions.

Finally, by neglecting the external costs of $\mathrm{CO}, \mathrm{HC}$ and $\mathrm{NO}_{\mathrm{x}}$, the expressions for the two quantities can be rewritten. Namely, the total cost for the average passenger car (14) and the total cost for the passenger car fleet in a country $k$, in a year $T_{i}(16)$ can be rewritten as:

$$
\begin{aligned}
C_{i, k} & =\frac{0.001}{N_{i, k}}\left[\sum_{h=1}^{5} N_{i, k, h} \cdot M_{i, k, h} \cdot w_{1, h} \cdot\left(\frac{e f_{i, k}}{a_{h}}+e c C O 2_{i}\right) \cdot\left(T_{i}-t_{i, k, h}-1994\right)^{w_{2, h}} \cdot\left(1+c_{h} \cdot t_{i, k, h}^{d_{h}}\right)\right]+ \\
& +\frac{e f_{i, k}}{N_{i, k}} \cdot \sum_{h=1}^{5} \frac{N_{i, k, h} \cdot b_{h}}{a_{h}}, E U R / \mathrm{km} .
\end{aligned}
$$




$$
\begin{aligned}
C F_{i, k} & =0.001\left[\sum_{h=1}^{5} N_{i, k, h} \cdot M_{i, k, h} \cdot w_{1, h} \cdot\left(\frac{e f_{i, k}}{a_{h}}+e c C O 2_{i}\right) \cdot\left(T_{i}-t_{i, k, h}-1994\right)^{w_{2, h}} \cdot\left(1+c_{h} \cdot t_{i, k, h}^{d_{h}}\right)\right]+ \\
& +e f_{i, k} \cdot \sum_{h=1}^{5} \frac{N_{i, k, h} \cdot b_{h}}{a_{h}}, E U R / k m .
\end{aligned}
$$

Based on Figure 2 and the Eq. (19), it can be concluded that we may reduce exhaust emissions and improve energy efficiency by decreasing the average age of passenger cars and average passenger car weight.

\subsection{Phase 3: Trends}

\subsubsection{The number of passenger cars}

Since 2001, the number of passenger cars has increased in many EU countries, such as Denmark and Spain (Eurostat, 2017). The same holds only partially for the fleet of Germany, because data indicates a sudden decrease in the number of passenger cars by $11 \%$ in 2007 . The same analysis applied to the Serbian passenger car fleet (Statistical Office of the Republic of Serbia, 2018) shows a decreased number of cars in two years: $2007(2 \%)$ and $2010(4 \%)$. Based on the analysis of the Serbian fleet, from the Statistical Office of the Republic of Serbia (2018), the number of the passenger cars for year $T_{i}$ was approximated based on data using regression analysis:

$$
N_{i, S R}=1417779+k_{N} \cdot\left(T_{i}-2004\right), \quad R^{2}=0.92 .
$$

where $k_{N}$ denotes the slope $-k_{N}=35985.38$. Based on the Eq. (20), it can be concluded that Serbia has a need to increase its fleet. The main question is: what kind of a passenger car supply would meet the above need? 


\subsubsection{The number of new passenger cars}

From the analysis of the results (Figure $3^{1}$ ), one concludes that the relation between the number of new passenger cars and the number of passenger cars increases with the GDP - the higher the GDP, the higher the demand for new cars is. Let us consider the cases of Serbia, France and Luxemburg 2012. Serbia had the lowest estimate of the relation between the number of new passenger cars and the number of passenger cars - 0.7. France and Luxemburg had higher values 5.9 and 14.4, respectively. The relation between the number of new passenger cars and the number of passenger cars and the GDP was approximated in this paper through a regression analysis:

$$
\frac{N n}{N}=1.8 \cdot 10^{-6} \cdot G D P+10^{-2},\left(R^{2}=0.7\right) .
$$

The contribution value of new passenger car price to the GDP of Serbia was approximately 0.57\% in 2013 (Mijailović, 2015), which is lower than contribution values for the EU countries. For example, the contribution value for Germany was 3-4\%, for Denmark approximately $2 \%$, for Italy $2-3 \%$, and for Greece $0.6-3 \%$ in the period of 2004-2015. The largest contribution was made in Luxembourg - approximately 4\%.

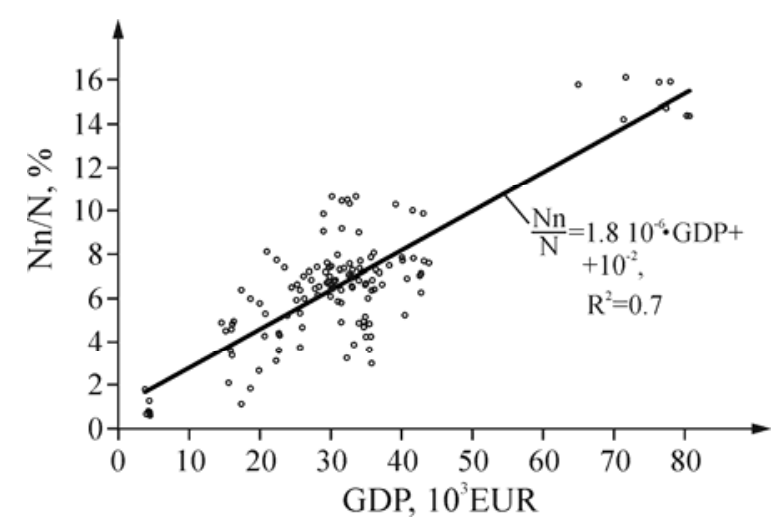

Figure 3. A relation between the number of new passenger cars and the number of passenger cars the GDP per capita (EU countries and Serbia)

${ }^{1}$ In Figure 3, the following references are used: GDP (The World Bank, 2017), the number of passenger cars (Eurostat, 2017) and the number of new passenger cars (Mock, 2014). 
Based on the analysis of the GDP change over the past ten years (Statistical Office of the Republic of Serbia, 2018), it is unrealistic to expect a significant increase of the GDP in Serbia in upcoming years. Additionally, considering economic limitations of the majority of the population in Serbia, an increase of the new cars share in Serbian fleet should not be expected.

\subsubsection{Trend - the number of second-hand passenger cars imported to a country}

The research carried out on a sample of passenger cars for 2008 showed that EU countries use different strategies to renew their passenger car fleets (Melhart et al, 2011). As proof of the previous conclusion, it indicates different values of the ratio of the second-hand imported passenger cars to new passenger cars for different countries. The highest values were found in the following EU countries: Poland (3.04), Bulgaria (2.98), Latvia (1.99) and Greece (1.38). Other EU countries had lower values: France and Portugal (0.04), Italy (0.03) and United Kingdom (0.01). For the EU, the ratio was 0.23 .

Analyzing the data provided by the Statistical Office of the Republic of Serbia (2018), the ratio of second-hand imported passenger cars to new passenger cars for Serbia is 1.41 for 2008. In the period that followed, that ratio trended higher with a maximum value for 2013 (10.93). In 2014, 2015 and 2016, the ratio trended lower, but was still significantly higher than in the EU countries. The main reasons for the above results are the government regulations. Namely, the Government of the Republic of Serbia adopted a regulation for importing second-hand cars at the end of 2005. It required that all second-hand imported passenger cars have at least a EURO 3 engine. As a result, the Serbian citizens were not allowed to buy the second-hand cars older than six years. This EURO limitation was abolished in April 2009. As a consequence of the new regulation, the ratio of the second-hand imported passenger cars to new passenger cars increased to 3.21 in 2009. In April 2014, the government reinstated the regulation, requiring all second-hand imported passenger cars have at least a EURO 3 engine, decreasing the ratio of second-hand imported passenger cars to new passenger cars to 6.86 in 2014. 
By analyzing the above results, it can be noticed that some car owners decided to buy secondhand passenger cars from foreign countries, instead of new passenger cars. Beydoun and Guldmann (2006) concluded that car age, fuel economy and weight have a significant influence on emissions. Therefore, it would be interesting to answer the question whether the import of second-hand passenger cars is an environmentally beneficial scenario for a country.

\subsection{Phase 4: Scenarios for a replacement of a passenger car fleet}

A replacement of old passenger cars with new passenger cars provides minimum values of exhaust emissions and maximum values of energy efficiency when the age of an old car is higher than its optimal lifetime. Some car owners decide to buy second-hand (used) cars, and replace old cars with newer models. If the age of the newer car is lower than its optimal lifetime, exhaust emissions will be reduced and energy efficiency will be improved. In the other case, one should scrap the old car. Some car owners decide to buy second-hand cars of ages higher than their optimal lifetimes. It can be noticed that car owners in some countries usually decide to import second-hand passenger cars. This is typical for the countries with the lowest GDP levels, such as Croatia, where the number of the second-hand imported passenger cars in 2016 was approximately five times higher than the number of the second-hand imported passenger cars in 2011 (before EU accession) (Rešetar et al., 2018). In addition, these countries have problems with waste recycling. The European Parliament and the Council formulated the EC Directive (Directive 2000/53/EC) addressing the ELV (ELV = End-of-Life Vehicles) issues. An additional problem is that the waste in those countries cannot be recycled in accordance with the EC Directive (Directive 2000/53/EC).

Reduction of a car weight results in reduced exhaust emissions and reduced fuel consumption (Zervas and Lazarou, 2008; Tolouei et al, 2009; Mijailović, 2013). The same applies to newer passenger cars (Heywood, 2011; Magueta et al., 2018). Bauer et al. (2015) concluded that the purchase of fossil-fuelled passenger cars cannot lead to the desired results. Therefore, it is also necessary to analyze the effectiveness of a reduction of the total number of the fossil-fuelled passenger cars in the fleet of a country. 
In line with the equations (16) and (19) and the conclusions above, a reduction of the total cost of a passenger car fleet can be achieved by considering the age of a car, size of a passenger car fleet, and a technical characteristic such as car weight. Thus, we analyze the following scenarios: current trend of the passenger car fleet development would remain the same (BAU scenario); new car buying scenario (NCBS scenario); import of the second-hand lower weight passenger cars (ISHM scenario); import of the newer second-hand passenger cars (ISHT scenario); scrappage incentive scenario (SCIS scenario); and a reduction of the total number of passenger cars in the fleet of a country (RTNC scenario).

\subsection{Phase 5: Evaluation of scenarios}

\subsubsection{BAU scenario - current trend of the passenger car fleet development would remain the same}

The BAU scenario is introduced under the assumption that the current trend of the passenger car fleet development would remain the same. The BAU scenario can also be found in literature under the name "Business As Usual" (Kwon, 2005). Based on the analysis of a sample of the passenger cars obtained by data collection in the inspection centers in 2015, we determined the average Serbian passenger car for the year 2015 (Table 2).

\begin{tabular}{|c|c|c|c|c|c|c|}
\hline$h$ & fuel type & $\begin{array}{c}\text { engine displacement, } \\
\mathrm{cm}^{3}\end{array}$ & $\begin{array}{c}t, \text { year } \\
(\text { age })\end{array}$ & $\begin{array}{c}M, \mathrm{~kg} \\
\text { (weight) }\end{array}$ & $\begin{array}{c}q f, \mathrm{l} / 100 \mathrm{~km} \\
\text { (specific fuel } \\
\text { consumption) }\end{array}$ & $\begin{array}{c}q C \mathrm{CO}_{2}, \mathrm{~g} / \mathrm{km} \\
\left(\text { specific } \mathrm{CO}_{2}\right. \\
\text { emission) }\end{array}$ \\
\hline 1 & petrol & $<1400$ & 16.7 & 926 & 6.8 & 162 \\
\hline 2 & petrol & $1400 \ldots 2000$ & 17.1 & 1176 & 8.2 & 196 \\
\hline 3 & petrol & $>2000$ & 19.8 & 1407 & 10 & 238 \\
\hline 4 & diesel & $<2000$ & 14.2 & 1225 & 6.6 & 176 \\
\hline 5 & diesel & $\geq 2000$ & 14.6 & 2202 & 9.5 & 256 \\
\hline
\end{tabular}

Table 2. The average Serbian passenger car for the year 2015

In Section 3.3.2, it was shown that the percentage of the purchased new passenger cars relative to the total number of passenger cars grows with an increase of GDP. Based on the analysis of GDP in Serbia over the past ten years, a large increase of GDP cannot be expected in the near future. The population of Serbia has relatively low purchasing power and is not able to allocate most of their revenues for the purchases of new passenger cars, so buying of second-hand imported 
cars becomes an attractive option for a large percentage of the population. This is in line with the finding that the share of new passenger car purchases in the GDP in Serbia is negligible. The number of the second-hand passenger cars imported to Serbia is several times higher than the number of purchased new passenger cars. For example, after 2010, the number of the second-hand imported passenger cars was approximately 100,000 cars per year with an average age of 9.3 years and an average price that is approximately four times lower than the price of a new car. Consequently, it cannot be expected that the replacement of passenger cars in the Serbian fleet can represent a solution for the problems related to energy efficiency and exhaust emissions of the passenger car fleet.

The analysis of data shows that the average age of the Serbian passenger car fleet was 15.6 years in 2014 and 16 years in 2015. Average ages of EU passenger car fleets have been increasing over the last 10 years (Rešetar et al., 2018). Based on the previous data, the average age of imported second-hand passenger cars is expected to increase in the future.

The second-hand imported passenger cars may decrease the average age of a passenger car fleet. This can be explained by the fact that the average age of the second-hand imported passenger cars is lower than the average age of the Serbian passenger car fleet. For example, the average age of the Serbian passenger car fleet was in the range of 14.2-19.8 years in 2015 (Table 2). In addition, the average age of the second-hand imported passenger cars was in much lower range of 8.9-11.8 years (Table 3). Based on these values, it can be concluded that the average age of the Serbian passenger car fleet is higher than the average age of the second-hand imported passenger cars by approximately $40 \%$.

\begin{tabular}{|c|c|c|c|}
\hline$h$ & fuel type & $\begin{array}{c}\text { engine displacement, } \\
\mathrm{cm}^{3}\end{array}$ & $\begin{array}{c}\text { The average age of the second- } \\
\text { hand imported passenger cars }\end{array}$ \\
\hline 1 & petrol & $<1400$ & 9.3 \\
\hline 2 & petrol & $1400 \ldots 2000$ & 9.8 \\
\hline 3 & petrol & $>2000$ & 11.8 \\
\hline 4 & diesel & $<2000$ & 8.9 \\
\hline 5 & diesel & $\geq 2000$ & 8.9 \\
\hline
\end{tabular}

Table 3. The average age of the second-hand imported passenger cars for the year 2015 
Lumbreras et al. (2008) found that scrappage incentives were some of the most efficient measures applied for exhaust emissions reduction. For example, the EU scrappage rate increased from 4.6\% to 4.85\% in the period of 2004-2009 (Mehlhart et al, 2011), and in 2020 it could reach 5.3\%. Croatia has lower values of the scrappage rate - between 3 and 3.5\% (Rešetar et al., 2018). The Serbian scrappage rate, on the other hand, decreased from approximately $13 \%$ in 2010 to $4 \%$ in 2015. This unusually high scrappage rate in 2010 was a consequence of a special promotional campaign for loyal customers conducted by the national "Zastava" company. The company offered a discounted price of new Zastava models to owners of old Zastava models, who agreed to dispose their old cars at a recycling center. Interestingly, after the replacement of old Zastava cars in the following year was exhausted, the scrappage rate was lower than $1 \%$. Thus, a renewal of the fleet with newer cars can provide good results when an adequate incentive to car owners is provided. Since 2011, the import of new cars became more attractive again, and scrappage rate increased slightly. This increase to $4 \%$ in 2015 can be associated with the introduction of new regulation on importing second-hand cars, which imposed stricter environmental requirements for the secondhand imported passenger cars - all second-hand imported passenger cars had to have at least an EURO 3 engine. Thus, the government import requirements also resulted in environmentally beneficial outcomes. The results related to the BAU scenario were obtained for a scrappage rate of $4 \%$.

Based on the sample analysis, it was also concluded that the second-hand imported passenger cars made up $36 \%$ in the Serbian passenger car fleet. While a large number of second-hand passenger cars was imported from EU countries such as Germany (37\%), Italy (23\%) and France (21\%), less than $3 \%$ of second-hand passenger cars was imported from countries outside the EU.

The fuel cost $\left(e f_{i, k}\right)$ was determined based on predictions of future trends in fuel costs. The first source we used was data related to changes in fuel costs in the period of 2006-2018, which were provided by the Statistical Office of the Republic of Serbia (2019). We assumed that the 
changes in fuel costs in the period of 2018-2025 followed the crude oil price forecast (The World Bank, 2019).

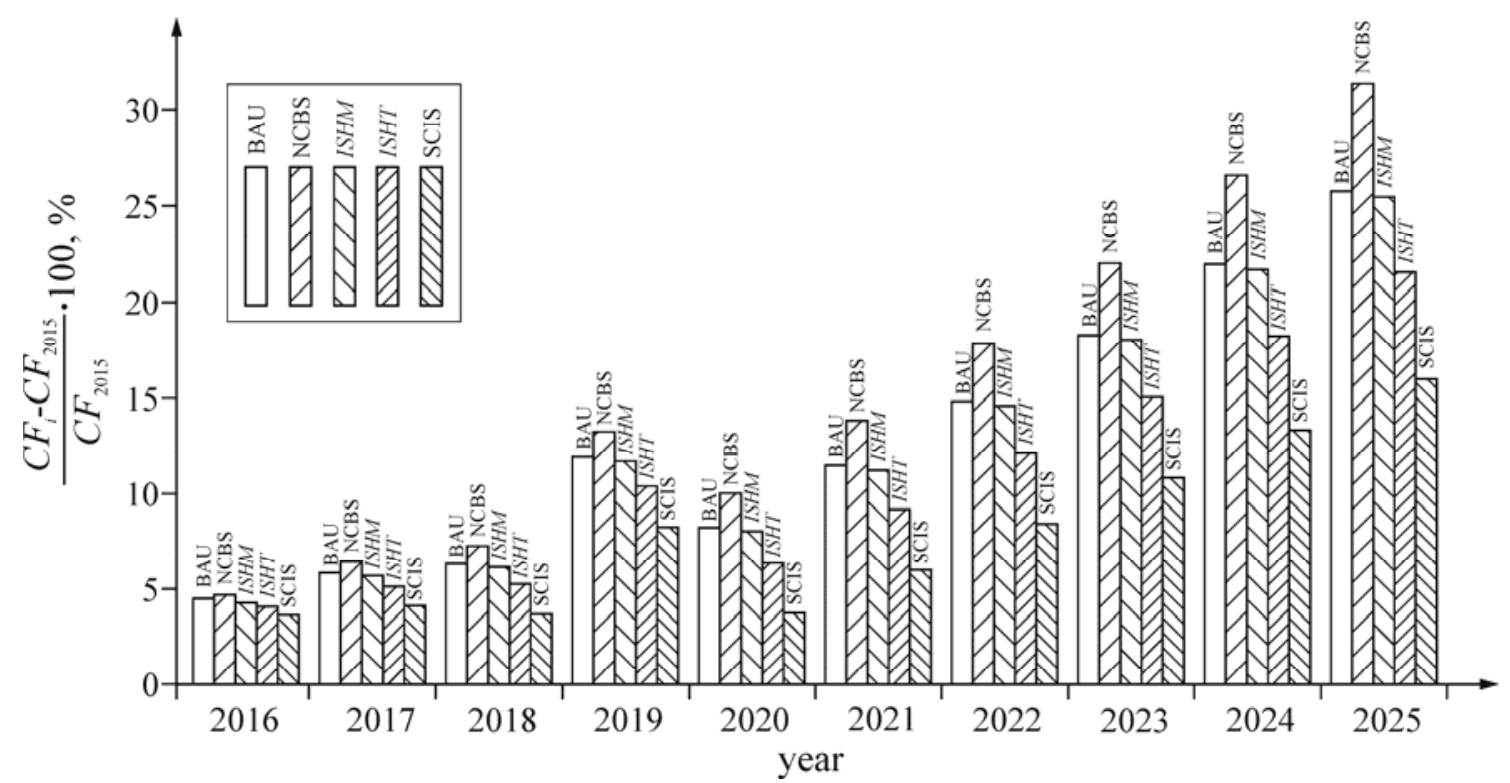

Figure 4. Forecasted effects of the following scenarios:

BAU, NCBS, ISHM $\left(\mu m_{i m}=15 \%\right)$, ISHT $\left(\mu t_{i m}=50 \%\right), \operatorname{SCIS}\left(\Delta s_{i, k, h}=0.05 ; \Delta i m_{i, k, h}=0\right)$

If the current trend of the passenger car fleet development continues (BAU), the total cost of the passenger car fleet will increase by $25.8 \%$ until 2025 , compared to the total cost of the passenger car fleet in 2015 (Figure 4). Analyzing the results, one concludes that the total cost of the passenger car fleet in 2019 is higher than in 2018 and 2020. This can be explained by predictions of future trends in fuel costs. According to the predictions, the fuel cost in 2019 is higher than the fuel costs in 2018 and 2020 by $2.8 \%$ and $6.7 \%$, respectively.

It was proven earlier that the fuel consumption cost has a major share in the total cost. Analyzing the results, the share of the fuel consumption cost in the total cost of the passenger car fleet has a minimal decreasing trend (approximately $0.16 \%$ per year). For example, the share will be $85.5 \%$ in 2020 and $84.7 \%$ in 2025 .

The specific emissions are not inspected during the import of second-hand cars. Second-hand car dealers issue no warranties, or issue them for a period of approximately six months. In addition, they often do not register car failures. There is a possibility for the specific emissions of the second- 
hand imported passenger cars to be higher than their expected values. In the relevant literature, we did not find any data about this issue. Therefore, we also analyzed the effect of emission deterioration due to the import of second-hand cars. Three cases were considered - emission increases of $10 \%, 20 \%$ and $30 \%$. Based on the analysis, we found that the negative effect is negligible. For example, if the specific emission of the second-hand imported passenger cars is $30 \%$ higher than its expected values, the total cost of the passenger car fleet will be $8.7 \%$ in 2020 and $26.4 \%$ in 2025 (BAU scenario $-8.3 \%$ in 2020 and $25.8 \%$ in 2025 ).

\subsubsection{NCBS scenario - new car buying scenario}

The "new car buying scenario" (NCBS) is based on the following assumptions: 1) there is no import of second-hand passenger cars, and 2) car owners buy new cars, not the second-hand cars. This assumption was practically applied considering that money which would otherwise be used for buying second-hand passenger cars is used for buying new passenger cars. The "new car buying scenario" assumes that new passenger cars are bought regardless of whether they were manufactured in Serbia or not.

By applying the NCBS scenario, the total cost of the passenger car fleet would be even more unfavourable than in the BAU scenario (Figure 4). A minimal difference between values of the total cost of the passenger car fleet in different years can be explained by the scrappage rate. Analysis showed that implementation of the NCBS scenario would result in a decrease of the scrappage rate (between $0.3 \%$ and $0.6 \%$ ). For example, the Serbian scrappage rate was approximately $4 \%$ in 2015 (BAU scenario). The above outcomes lead to the conclusion that, in the case of the NCBS scenario, a positive effect of buying new cars would be annulled by keeping the old cars that would be withdrawn from use in the case of the current trend (BAU).

\subsubsection{ISHM scenario - import of the second-hand lower weight passenger cars}

A decrease of a passenger car weight has benefit for $\mathrm{CO}_{2}$ emissions (Zervas and Lazarou, 2008). On the other hand, Usón et al (2011) concluded that consumer markets show an increasing 
trend to bigger and heavier vehicles. This conclusion is compatible with Mijailović (2013), where a functional dependence was determined between car weight and the year of production. According to the current trend, the average weight of passenger cars in Serbia will be approximately $2.4 \%$ higher in 2020, compared to 2015. The average weight of the second-hand passenger cars imported to Serbia is higher than the average weight of the passenger cars already existing in the fleet of Serbia. This discrepancy is expected to be approximately $6.4 \%$ in 2020 .

In order to investigate whether weight reduction of second-hand imported passenger cars can contribute to environmental benefits, we analyzed three cases - weight reduction of the secondhand imported passenger cars $\left(\mu m_{i m}\right): 5 \%, 10 \%$ and $15 \%$. The cases were analysed in relation to the current trend of the passenger car fleet development (BAU). The results for $\mu m_{i m}=15 \%$ are presented in Figure 4. The results show that despite the reduction of the average weight of the second-hand imported passenger cars, there is no significant reduction in the total cost of the passenger car fleet. For example, according to the current trend, the total cost of the passenger car fleet would increase to $8.3 \%$ in 2020 and to $25.8 \%$ in 2025 . In the case of ISHM scenario and for $\mu m_{i m}=15 \%$, the total cost of the passenger car fleet would increase to $8 \%$ in 2020 and to $25.5 \%$ in 2025. Based on additional analysis, we found that, even for an unrealistic weight reduction of $50 \%$, the total cost of the passenger car fleet would increase to $7.6 \%$ in 2020 . The main reason is that the weight reduction of the second-hand imported passenger cars $\left(\mu m_{i m}\right)$ has minimal impact on the average weight of the Serbian passenger car fleet. For example, if we reduce the average weight of the second-hand imported passenger cars by $50 \%$, the average weight of the Serbian passenger car fleet will decrease by only $2.5 \%$ approximately in 2020 . The analysis leads to the conclusion that exhaust emissions cannot be significantly reduced, nor can energy efficiency be significantly improved by applying the ISHM scenario in Serbia. 


\subsubsection{ISHT scenario - import of the newer second-hand passenger cars}

In the above sections we found that: 1) the average age of second-hand imported passenger cars in Serbia is approximately equal to the average age of the EU passenger cars, and 2) the average age of the Serbian passenger car fleet is higher than the average age of second-hand imported passenger cars. In order to investigate whether a reduction of the average age of the second-hand imported passenger cars might have positive environmental effects, we introduce three age reduction scenarios for the second-hand imported passenger cars $\left(\mu t_{i m}\right): 10 \%, 30 \%$ and $50 \%$. These scenarios are analysed in relation to the current trend of the passenger car fleet development (BAU). The results for $\mu t_{i m}=50 \%$ are presented in Figure 4 .

The analysis shows that the impact of imports of the newer second-hand cars to Serbia is more positive than in the NCBS and ISHM scenarios. For example, in the case of the ISHT scenario and for $\mu t_{i m}=30 \%$, the total cost of the passenger car fleet would increase to $7.1 \%$ in 2020 and to $23.2 \%$ in 2025 (BAU scenario $-8.3 \%$ in 2020 and to $25.5 \%$ in 2025 ). In the case of the ISHT scenario and for $\mu t_{i m}=50 \%$, the total cost of the passenger car fleet would increase to $6.4 \%$ in 2020 and to $21.6 \%$ in 2025 . That way, the positive effects on exhaust emissions and energy efficiency in the ISHT scenario would be better than in the BAU, NCBS and ISHM scenarios. In addition, the total cost of the passenger car fleet exhibits an increasing trend in the case of ISHT scenario. Therefore, it can be concluded that the ISHT scenario cannot achieve satisfactory results.

\subsubsection{SCIS scenario - scrappage incentive scenario}

In order to investigate whether scrappage incentive can contribute to environmental benefits, we analyzed two cases. The first case (SCISc1) is based on assumptions that there is no import of the second-hand passenger cars $\left(\Delta i m_{i, k, h}=0\right)$ and, therefore, the purchasing power of the population is ignored. For that reason, a fleet increase trend and an increasing value of the scrappage rate were achieved only by purchasing new passenger cars. The difference between the first case (SCISc1) 
and the second case (SCISc2) is in the fact that the existing rate value of second-hand passenger cars $\left(\Delta i m_{i, k, h}\right)$ is kept in the second scenario.

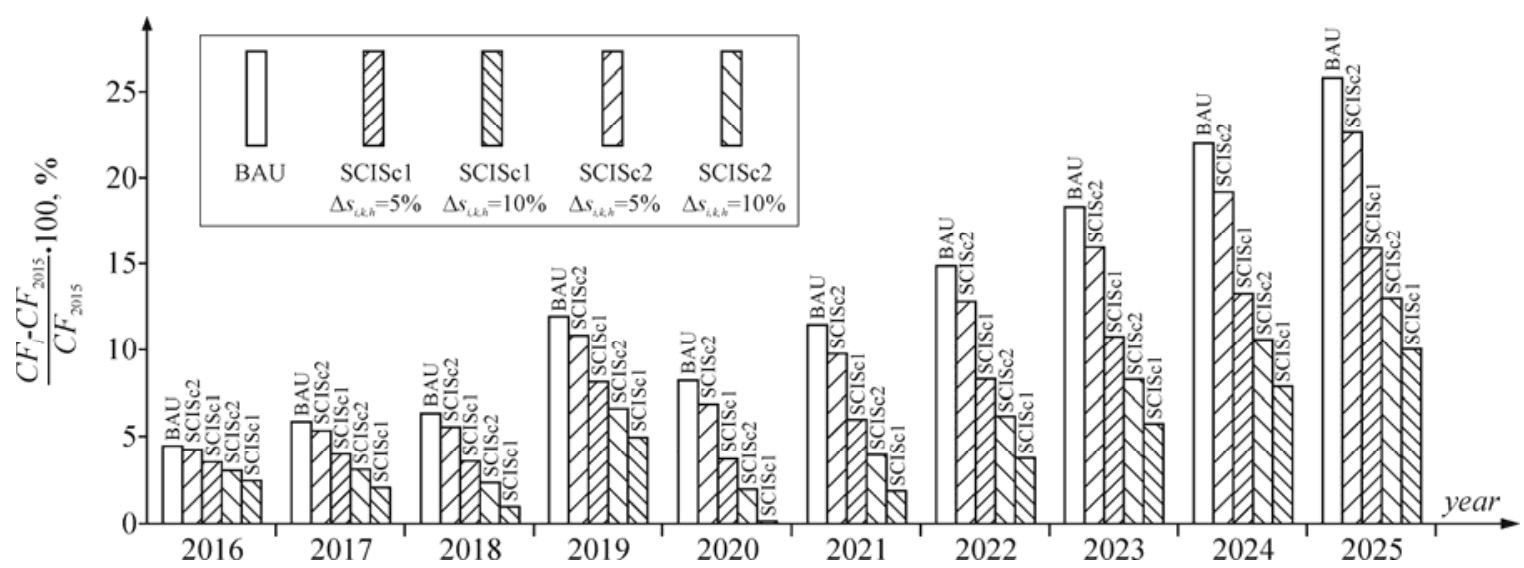

Figure 5. Forecasted effects of the SCIS scenarios

The positive effects of the SCIS scenario rise with the increase of the scrappage rate. The above conclusion is valid in both cases (Figure 5). The analysis also shows that the impact of the SCISc1 scenario is higher than the impact of the SCISc2 scenario. For example, in the SCISc1 scenario and for $\Delta s_{i, k, h}=5 \%$, the total cost of the passenger car fleet would increase to $3.7 \%$ in 2020 and to $15.9 \%$ in 2025 (BAU scenario $-8.3 \%$ in 2020 and to $25.5 \%$ in 2025 ). In the SCISc2 scenario and for $\Delta s_{i, k, h}=5 \%$, the total cost of the passenger car fleet would increase to $6.9 \%$ in 2020 and to $22.7 \%$ in 2025 . The problems of implementing the SCIS strategy in practice are unrealistically high values of the rate of buying new passenger cars $\left(\Delta n_{i, k, h}\right)$. For example, in the SCISc1 scenario and for $\Delta s_{i, k, h}=5 \%$ and $\Delta s_{i, k, h}=10 \%$, the rate of buying new passenger cars is higher than its value in the BAU scenario for approximately 7 and 12 times, respectively. In the case of the SCISc2 scenario, smaller increases are obtained - for approximately $2\left(\Delta s_{i, k, h}=5 \%\right)$ and 7 times $\left(\Delta s_{i, k, h}=10 \%\right)$.

The analysis shows that the impact of the scrappage incentive scenario may be more positive than the impact of the NCBS, ISHM and ISHT scenarios (Figure 4). In addition, the total cost of the passenger car fleet has an increasing trend in the case of the SCIS scenario. Therefore, it can be concluded that the SCIS scenario cannot achieve satisfactory results. 


\subsubsection{RTNC scenario - reduction of the total number of passenger cars in the fleet of a country}

Our data shows that the number of passenger cars in Serbia increases in each subsequent year. The same conclusion can be drawn from analysing the results presented in Figure 6 (BAU scenario $-k_{N}=35985.38$ ). Figure 6 shows a dependence of the number of passenger cars in Serbia upon year for different values of rates reduction $\left(k_{N}\right)$. Figure 6 also shows the results from the RTNC scenario. For example, for $k_{N}=0$, a fleet size does not change. If we analyze the case for $k_{N}=-35985.38$ (RTNC scenario), the number of passenger cars in Serbia in 2025 will be smaller by approximately 720,000 cars compared to the BAU scenario. The difference between numbers of passenger cars in Serbia in 2025 and for $k_{N}=0$ and $k_{N}=35985.38$ is approximately 360,000 cars.

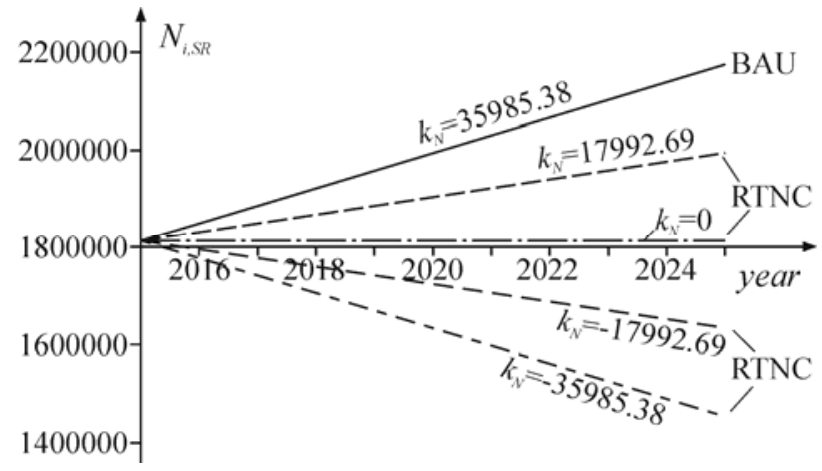

Figure 6. Dependence of the number of passenger cars - year of the Serbian passenger car fleet

By analyzing the ISHM and ISHT scenarios, we concluded that imports of lower weight or newer second-hand passenger cars cannot achieve satisfactory results. As the number of secondhand passenger cars exported from Serbia is negligible, an implementation of the ISHM and ISHT scenarios would actually result in an increase in generated waste when a car completes its life cycle. 


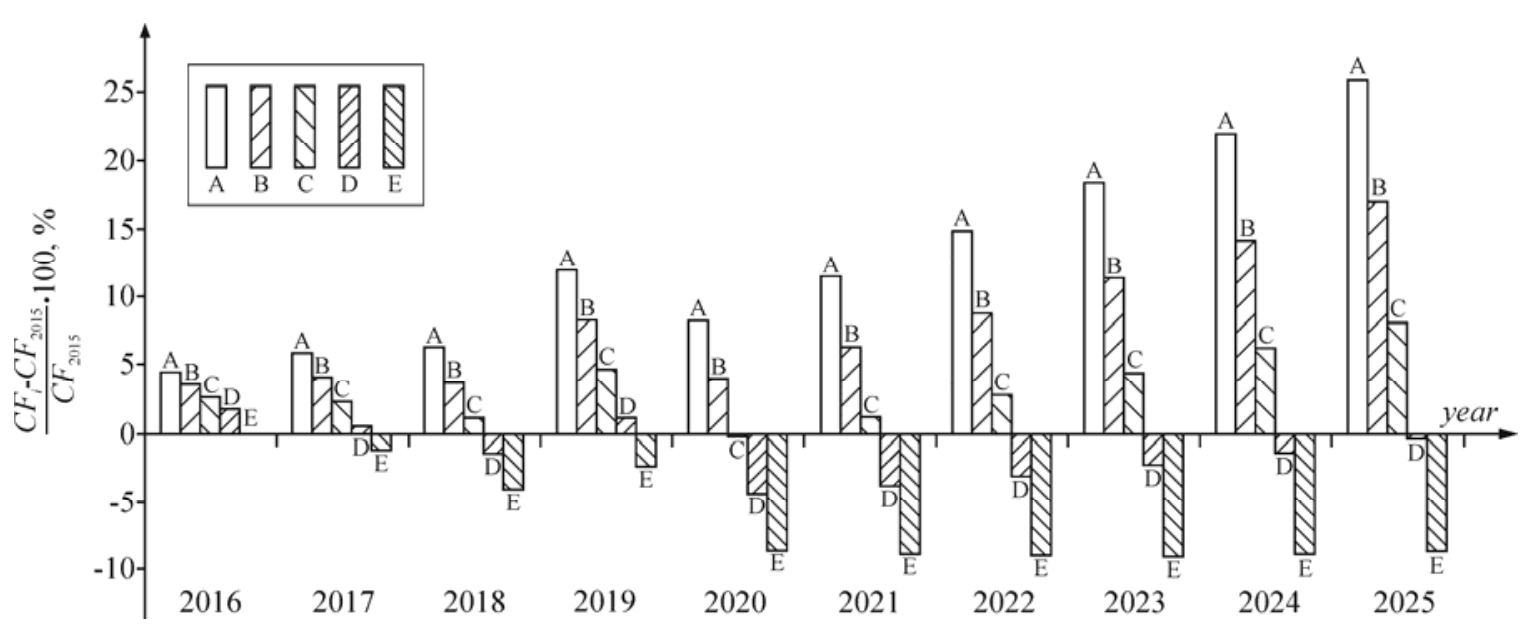

Figure 7. Forecasted effects of the RTNC scenario
$\left(\mathrm{A}: k_{N}=35985.38\right.$
B: $k_{N}=17992.69$
$\mathrm{C}: k_{N}=0$;
$\mathrm{D}: k_{N}=-17992.69$
$\left.\mathrm{E}: k_{N}=-35985.38\right)$

In order to investigate whether a reduction of the total number of cars in the fleet of a country might result in environmental benefits, we analysed different values of rates reduction (Figure 7). A reduction of the total number of cars in a fleet can be achieved by reducing the number of the second-hand imported passenger cars. By analyzing the results, it may be concluded that the total cost of the passenger car fleet for $k_{N}=0$ (fleet size does not change) has a predominantly increasing trend. Positive effects may be achieved only if the total number of cars in a fleet is reduced. For example, in the case of the RTNC scenario and for $k_{N}=-35985.38$, the total cost of the passenger car fleet would decrease by approximately $8.7 \%$ after 2020 . In the case of the RTNC scenario and for $k_{N}=-17992.69$, the total cost of the passenger car fleet would decrease by $4.5 \%$ in 2020 . The positive effect of the RTNC scenario and for $k_{N}=17992.69$ will be lower after 2020. For example, the total cost of the passenger car fleet would decrease by only $0.4 \%$ in 2025 . These results may be explained by the increasing effect of the average age of the Serbian passenger car fleet, as well as by emissions and fuel consumption deterioration with the age of passenger cars. Based on the results presented in Figure 7, the following conclusion can be drawn: a reduction of the total number of cars in the passenger car fleet of a country has a positive effect on solving the problems related to energy efficiency and exhaust emissions of a passenger car fleet $\left(k_{N}<0\right)$.

By comparing the NCBS, ISHM, ISHT, SCIS and RTNC scenarios, it can be concluded that positive results can be obtained only by a reduction of the total number of passenger cars in the fleet 
of a country (RTNC). The application of this scenario is in contradiction to a tendency of increasing the size of the passenger car fleet of Serbia. In order to meet both requirements - a need for reduction of total costs and environmental impact on the one hand, and a rising demand for passenger cars, on the other, - it is necessary to look for other solutions, such as alternative-fuelled cars. A similar conclusion can be found in the literature: "substantial mitigation of climate change can be obtained with electric passenger vehicles, provided that non-fossil energy resources are used for electricity and hydrogen production" (Bauer et al., 2015, p. 871). In this paper, a scenario for buying alternative-fuelled cars has not been analyzed because the countries with lower GDP, such as Serbia, do not have a developed infrastructure that would support use of such cars.

The obtained numerical data and performed analysis will be made available by authors upon request.

\section{Conclusion, limitations and future research}

Energy efficiency improvement and exhaust emissions reduction are environmental tasks of the utmost importance in the transport and traffic sectors. In order to manage the fleet of a country, different scenarios are considered. However, the literature does not offer any methodology that aids the selection of scenarios providing the best results. In this study, we developed a methodology to determine and evaluate the effects of selected scenarios with regard to environmental benefits. Our methodology defines environmental benefits by considering the energy efficiency of cars and their exhaust emissions.

The methodology represents the main contribution of this study, and is based on a determination of the external costs of the $\mathrm{CO}_{2}, \mathrm{CO}, \mathrm{NO}_{x}$ and $\mathrm{HC}$ emissions, as well as of the cost of fuel consumption. Moreover, we indirectly considered a technological development of the car industry with regard to technical solutions for the $\mathrm{CO}_{2}$ emissions reduction and car design, i.e. we considered the engine type, year of production and weight of cars. An economic impact is included through the consideration of a country's GDP. The methodology also included the effect of 
emissions deterioration with the age of passenger cars. This consideration of both technological and economic factors is a step forward in methodological design, since in earlier studies a methodology was focused only on one type of factors (Kwon, 2005; Zervas and Lazarou, 2008), or considered only a few factors (Zachariadis et al., 2001; Mitropoulos and Prevedouros, 2015; Kim et al., 2004). Hence, compared to other research, our research solves the problem by including a larger number of factors in the analysis. Moreover, the developed methodology is general. In this paper, we tested the methodology for the case of Serbia. Serbia belongs to the group of countries where the number of the second-hand imported passenger cars is typically several times higher than the number of new passenger cars in each observed year. Therefore, conclusions obtained in this study can be applied to similar countries.

The second contribution of this study is a deeper insight into the structure of the Serbian passenger car fleet than the insights provided through the use of national statistical data. The empirical research conducted in 2014 and 2015 provided us with relevant technical and economic data that enabled development and application of the proposed methodology.

The third contribution of this paper is in the six analyzed scenarios used to apply the methodology. The additional contribution is the fact that this is one of the first studies which analyze in detail an impact of second-hand passenger cars on energy efficiency and exhaust emissions of a passenger car fleet.

The main limitation of this research is that we only analyzed fossil-fuelled passenger cars. This has a negligible effect on the accuracy of obtained results, as the number of alternative-fuelled (e.g. electric) cars is negligible in relation to the total number of cars. In line with the main conclusion of this study, it is necessary to reduce the number of fossil-fuelled passenger cars in order to satisfy the growing demand and to obtain environmental benefits at the same time.

Road transport has the biggest share in greenhouse gases emissions of the transport sector. The share was approximately 70\% in 2014 (Eurostat, 2019a). The contribution of a car's emissions is approximately $12 \%$ in the total EU emissions of $\mathrm{CO}_{2}$ (Eurostat, 2019b). Heavy-duty vehicles also 
have high contribution in the total EU emissions of $\mathrm{CO}_{2}-$ approximately $6 \%$ (Eurostat, 2019c). The proposed methodology may also be applied to heavy-duty vehicles, with some modifications. Accordingly, a functional relationship between the specific $\mathrm{CO}_{2}$ emission, average heavy-duty vehicle weight and a year (Eq. 6) must be determined. Application of the methodology on heavyduty vehicles is even more important for countries like Serbia, in which demand for heavy-duty vehicles is met mostly by importing second-hand heavy-duty vehicles. Within the scope of future research, the methodology will be applied to heavy-duty vehicles.

Future research should also explore the conditions (economic, infrastructural, legislative etc.) necessary to reduce the number of fossil-fuelled passenger cars and to increase the number of alternative-fuelled cars. In that sense, a special focus should be put on electric cars. In addition, future research has to be focused on analyzing a potential for a fleet reduction by introducing new concepts of organization in transport systems, such as car sharing. Within the scope of future research, the methodology can also be tested on passenger car fleets of other countries. In addition, future research should focus on the data obtained by monitoring the real technical condition of cars in the Serbian fleet. This will be enabled through a change of the relevant legislation in Serbia. Since 2018, the annual car testing also includes emissions testing. This will help researchers to design a database for more accurate measuring of ecological footprint of the passenger car fleet. This prospect research can be focused on a development of a new general methodology aimed to resolve the problems of energy efficiency improvement and exhaust emissions reduction of the road fleet. The new methodology would achieve improvement in the following directions. First, the methodology would include different types of vehicles, such as passenger cars, buses and heavyduty vehicles. Second, besides traditional modes of transportation based on the use of private cars, or any other kind of public transport (buses, trams, taxi etc.), several concepts have been developed to make the transport system more efficient such as car-pooling, car sharing, park-and-ride etc. Third, the methodology can be extended by considering different types of fuels, i.e. vehicles, in the analysis. In that case, the fleet of vehicles would be analyzed in such a way as it consists of fossil- 
fuelled and alternative-fuelled vehicles (electric cars, biofuels, natural gas etc.). Additionally, the methodology should also include an economic analysis of all phases of a vehicle life cycle.

Acknowledgement. The research presented in this paper has been realized in the framework of the technological projects financed by the Ministry of Education, Science and Technological Development of the Republic of Serbia (Grant No. TR 36010 and TR 36027). The authors would like to thank the editor and three anonymous reviewers for their helpful comments and valuable suggestions. The authors gratefully acknowledge N. Cvetanović for his assistance in improving the text. 


\section{References}

[1] Bauer C., Hofer J., Althaus HJ., Del Duce A., Simons A., 2015. The environmental performance of current and future passenger vehicles: Life cycle assessment based on a novel scenario analysis framework, Applied Energy, 157, pp. 871-883

[2] Beydoun M., Guldmann, JM., 2006. Vehicle characteristics and emissions: Logit and regression analyses of I/M data from Massachusetts, Maryland, and Illinois, Transportation Research Part D, 11, pp. 59-76, doi:10.1016/j.trd.2005.09.003

[3] Borken-Kleefeld, J., Chen, Y., 2015. New emission deterioration rates for gasoline cars Results from long-term measurements, Atmospheric Environment, 101, pp. 58-64, doi: 10.1016/j.atmosenv.2014.11.013

[4] Cheah L., Heywood J., 2011. Meeting U.S. passenger vehicle fuel economy standards in 2016 and beyond, Energy Policy, 39, pp. 454-466, doi:10.1016/j.enpol.2010.10.027

[5] Directive 2000/53/EC of the European Parliament and of the Council on end-of life vehicles, Official Journal L 269, 2000.

[6] Eurostat, 2017. http://ec.europa.eu/eurostat/web/transport/data/database, accessed: 2017/06/15

[7] Eurostat, 2019a. https://ec.europa.eu/clima/policies/transport, accessed: 2019/01/07

[8] Eurostat, 2019b. https://ec.europa.eu/clima/policies/transport/vehicles/cars_en, accessed: 2019/01/07

[9] Eurostat, 2019c. https://ec.europa.eu/clima/policies/transport/vehicles_en, accessed: $2019 / 01 / 07$

[10] Fontaras G., Samaras Z., 2007. A quantitative analysis of the European Automakers' voluntary commitment to reduce $\mathrm{CO}_{2}$ emissions from new passenger cars based on independent experimental data, Energy Policy, 35, pp. 2239-2248, doi:10.1016/j.enpol.2006.07.012 
[11] Hao H., Geng Y., Sarkis J., 2016. Carbon footprint of global passenger cars: Scenarios through 2050, Energy, 101, pp. 121-131, doi: 10.1016/j.energy.2016.01.089

[12] Kaplanović S., Mijailović R, 2012. The internalisation of external costs of $\mathrm{CO}_{2}$ and pollutant emissions from passenger cars, Technological and economic development of economy, 18/3, pp. 470-486, doi:10.3846/20294913.2012.702694

[13] Kim H.C., Ross M.H., Keoleian G.A., 2004. Optimal fleet conversion policy from a life cycle perspective, Transportation Research Part D, 9, pp. 229-249, doi: 10.1016/j.trd.2004.02.004

[14] Kwon T.H., 2005. A scenario analysis of $\mathrm{CO}_{2}$ emission trends from car travel: Great Britain 2000-2030. Transport Policy, 12, pp. 175-184, doi: 10.1016/j.tranpol.2005.01.004

[15] Lumbreras J., Valdes M., Borge R., Rodrıguez M.E., 2008. Assessment of vehicle emissions projections in Madrid (Spain) from 2004 to 2012 considering several control strategies, Transportation Research Part A, 42, pp. 646-658, doi: 10.1016/j.tra.2008.01.026

[16] Magueta D., Madaleno M., Dias M.F., Meireles M., 2018. New cars and emissions: Effects of policies, macroeconomic impacts and cities characteristics in Portugal, Journal of Cleaner Production, 181, pp. 178-191, doi: 10.1016/j.jclepro.2017.11.243

[17] Mickunaitis V., Pikunas A., Mackoit I., 2007. Reducing fuel consumption and $\mathrm{CO}_{2}$ emission in motor cars, Transport, Vol. XXII, No. 3, pp. 160-163, doi: $10.1080 / 16484142.2007 .9638119$

[18] Mijailović R., 2013. The optimal lifetime of passenger cars based on minimization of $\mathrm{CO}_{2}$ emission, Energy, Vol. 55, pp. 869-878, doi: 10.1016/j.energy.2013.04.008

[19] Mijailović R., 2015. Serbian passenger cars fleet renewal management, International scientific conference of IT and business related research "Synthesis", Belgrade, 16-17 April 2015, pp. 181-185, doi: 10.15308/Synthesis-2015-181-185 
[20] Mitropoulos L.K., Prevedouros P.D., 2015. Life cycle emissions and cost model for urban light duty vehicles, Transportation Research Part D, 41, pp. 147-159, doi: 10.1016/j.trd.2015.09.024

[21] Melhart G., Merz C., Akkermans L., Jordal-Jorgensen J., 2011. European second-hand car market analysis, Report

[22] Mock P., 2014. European vehicle market statistics, Berlin, International Council on Clean Transportation Europe, Report

[23] Olsthoorn X., 2003. Implications of globalization for $\mathrm{CO}_{2}$ emissions from transport, Transportation Planning and Technology, Vol. 26, No. 1, pp. 105-133, doi:10.1080/03081060309909

[24] Rešetar M., Pejić G., Lulić Z., 2018. Changes and trends in the Croatian road vehicle fleet Need for change of policy measures, Transport Policy, 71, pp. 92-105, doi:10.1016/j.tranpol.2018.08.005

[25] Schipper L., 2011. Automobile use, fuel economy and $\mathrm{CO}_{2}$ emissions in industrialized countries: Encouraging trends throug 2008?, Transport Policy, 18, 2011, pp. 358-372, doi:10.1016/j.tranpol.2010.10.011

[26] Statistical Office of the Republic of Serbia, 2018. www.stat.gov.rs, accessed: 2018/04/29

[27] Statistical Office of the Republic of Serbia, 2019. www.stat.gov.rs, accessed: 2019/01/11

[28] The World Bank, 2017. https://data.worldbank.org/, accessed: 2018/04/29

[29] The World Bank, 2019. http://pubdocs.worldbank.org/en/823461540394173663/CMOOctober-2018-Forecasts.pdf, accessed: 2019/01/11

[30] Tolouei R., Titheridge H., 2009. Vehicle mass as a determinant of fuel consumption and secondary safety performance, Transportation Research Part D, 14, pp. 385-399

[31] Usón A.A., Capilla A.V., Bribián I.Z., Scarpellini S, 2011. Sastresa EL. Energy efficiency in transport and mobility from an eco-efficiency viewpoint, Energy, 36, pp. 1916-1923 
[32] Vinoles-Cebolla R., Bastante-Ceca M.J., Capuz-Rizo S.F., 2015. An integrated method to calculate an automobile's emissions throughout its life cycle, Energy, 83, pp. 125-136, doi: 10.1016/j.energy.2015.02.006

[33] Zachariadis T., Ntziachristos L. \& Samaras Z., 2001. The effect of age and technological change on motor vehicle emissions. Transportation Research Part D, 6, pp. 221-227, doi: 10.1016/S1361-9209(00)00025-0

[34] Zervas E., 2010. Analysis of the CO2 emissions and of the other characteristics of the European market of new passenger cars. 1. Analysis of general data and analysis per country, Energy Policy, 38, pp. 5413-5425

[35] Zervas E., Lazarou C., 2008. Influence of European passenger cars weight to exhaust $\mathrm{CO}_{2}$ emissions, Energy Policy, 36, pp. 248-257, doi:10.1016/j.enpol.2007.09.009 